\title{
Etiology of Short Stature in First Five Years of Life
}

\author{
Kobra Shiasi-Arani ${ }^{1, *}$ \\ ${ }^{1}$ Research Center for Biochemistry and Nutrition in Metabolic Diseases, Kashan University of Medical Sciences, Kashan, IR Iran \\ "Corresponding author: Kobra Shiasi-Arani, Research Center for Biochemistry and Nutrition in Metabolic Diseases, Kashan University of Medical Sciences, Kashan, IR Iran. \\ E-mail: kobra.shiasi@gmail.com
}

Received 2015 January 24; Accepted 2015 April 2.

Keywords: Short Stature, Etiology, Diagnostics

\section{Dear Editor,}

Short stature (SS) is one of the common causes of referrals to pediatric endocrinologists. The most common causes of SS included familial SS and constitutional growth delay, but a wide spectrum of the diseases can result to SS. It is evident that the correct understanding of the etiology of short stature in any society can be a good guide for diagnostic and therapeutic policies. So, many endocrine centers attempted to study the etiology of SS in their areas. This is a descriptive study and conducted in Kashan University of Medical Sciences. Any child under 5 years with a height less than the 3rd percentile of standard growth curves has been enrolled. Data including age, gender, family history of short stature, history of chronic diseases such as bowel disease, malnutrition, celiac disease and drug history from the parents or the child were obtained. The height and weight of the children and parents were measured. The physical examination was performed to find the cause of short stature. Preliminary tests were performed for all children including $\mathrm{CBC}$, thyroid function tests, electrolytes, urinalysis and creatinine. Other tests based on the suspected disorders. A left wrist and hand X-ray was performed for all cases to determine bone age and evidences of bone dysplasia. A total of 67 children were included, the mean age was $2.5 \pm 1.45$ years (39 male and 28 female). Average height was $77.36 \pm 14.6 \mathrm{~cm}$ and mean weight was $9.26 \pm 3.4 \mathrm{~kg}$. Overall the most common cause was short stature in a background of low birth weight (LBW) (23.9\%) followed by constitutional growth delay (14.9\%), familial short stature (11.9\%) and growth hormone deficiency (10.5\%).

Most common causes of short stature in different age groups included:

0 - 2 years: Short stature in a background of low birth weight was the most common $(n=12,44.4 \%)$ followed by the metabolic disorders and syndromes each of the 4 patients (14.8\%).

2-5 years: Familial short stature (20.5\%), different syn- dromes (20.5\%) and constitutional short stature (17.9\%).

Metabolic disorders: Cystinosis, phenylketoneuria and organic academia.

Syndromes: Down syndrome (most common), Noonan syndrome, Turner syndrome and unknown syndromes. Other causes: Nephrogenic diabetes insipidus, pycnodysostosis, chronic hepatitis, achondroplasia and hypochondroplasia. One case of hypochondroplasia also had hypothyroidism. One patient with achondroplasia had also growth hormone deficiency. Growth hormone deficiency is a quietly treatable cause of short stature in children and had a relatively high prevalence in our study (10.5\%). Growth hormone deficiency has been reported in other studies with a prevalence of $34.3 \%$ in Majcher et al. study, $15 \%$ in Chowdhury et al. study and 30\% in Mohammadian et al. study [1-3]. An interest finding in our study was the association of two important cause of short stature in some cases such as hypothyroidism in a girl with achondroplasia and growth hormone deficiency in another girl. The prevalence of chromosomal abnormalities in our work was relatively high (9\%) and Down syndrome was the most common disorder. A prevalence of $20 \%$ of chromosomal abnormalities in short stature children also has been reported [2].

\section{References}

1. Majcher A, Bielecka-Jasiocha J, Pyrzak B. Analysis of reasons of short stature in own material. Pediatr Endocrinol Diabetes Metab. 2009;15(3):152-6. [PubMed: 20384174].

2. Chowdhury SP, Sarkar TK, Haldar D, Taraphdar P, Naskar TK, Sarkar GN. Short stature in children: Experience from a tertiary care hospital in Kolkata, India. Health. 2011;2(4):139-42.

3. Mohammadian S, Khoddam H, Nematollahi MR. The causes of short stature among children in Gorgan-Iran [in Persian]. J Gorgan Univ Med Sci. 2008;10(3):56-70. 